\title{
Chemical defense of Pterogorgia anceps, a Caribbean gorgonian coral
}

\author{
Joseph R. Pawlik' ${ }^{1}$ William Fenical ${ }^{2}$ \\ ${ }^{1}$ Department of Biological Sciences and Center for Marine Science Research, University of North Carolina at Wilmington, \\ Wilmington, North Carolina 28403-3297, USA \\ ${ }^{2}$ University of California, San Diego, Scripps Institution of Oceanography, La Jolla, California 92093-0236, USA
}

\begin{abstract}
Field and laboratory experiments confirmed the feeding-deterrent properties of lipidsoluble extracts of the Caribbean gorgonian octocoral Pterogorgia anceps (Pallas) with subsequent determination of the secondary metabolite responsible for this effect. A dichloromethane/methanol extract of $P$. anceps incorporated into carrageenan food strips at the same volumetric concentration as the extract occurred in gorgonian tissues deterred feeding of a natural assemblage of fishes on the same reef from which the gorgonian was collected. Bioassay-directed fractionation of this extract revealed that the deterrent property was restricted to an ancepsenolide-containing fraction; there was no effect of the less polar hydrocarbon fraction or the more polar pigmented fraction. Field assays of the ancepsenolide-containing fraction at the same volumetric concentration as it occurred in gorgonian tissues confirmed that it deterred predation by reef fishes. Laboratory assays of purified metabolites isolated from the ancepsenolide-containing fraction revealed that the feeding-inhibitory effect was restricted to a diacetoxy derivative of ancepsenolide; neither ancepsenolide nor its monoacetoxy derivative were deterrent when assayed alone or in combination. This represents the first evidence of feeding-deterrence by gorgonian metabolites of the unusual acetogenin class.
\end{abstract}

\section{INTRODUCTION}

For over 2 decades, marine natural products chemists have isolated and identified unusual secondary metabolites from the tissues of soft corals (Octocorallia; reviews in Fenical 1982, Faulkner 1991, and previous reviews by the same author). While the pharmacological effects of some of these compounds were promptly investigated (e.g. Weinheimer \& Matson 1975, McEnroe \& Fenical 1978), the ecological roles of these metabolites were not addressed by employing relevant laboratory and field experiments until recently (gorgonians: Gerhart 1984, Pawlik et al. 1987, Harvell et al. 1988, Harvell \& Fenical 1989, Pawlik \& Fenical 1989, Fenical \& Pawlik 1991; alcyonaceans: Wylie \& Paul 1989).

Gorgonian corals appear to be excellent candidates for the elaboration of chemical defenses: (1) they are abundant on tropical coral reefs, reaching densities of 25 colonies $\mathrm{m}^{-2}$ in the Caribbean (Goldberg 1973); (2) their soft tissues provide a readily available source of food to potential predators; (3) their preferred habitat is noted for high levels of predation and nutrient scarcity (Grigg et al. 1984, Huston 1985). Despite a few specialists (ovulid molluscs: Gerhart 1986, Harvell \& Suchanek 1987, Lasker \& Coffroth 1988; polychaete: Vreeland \& Lasker 1989; butterflyfish: Lasker 1985), gorgonians appear to be largely free from predation.

Previously, we surveyed the feeding deterrence of lipid-soluble extracts of Caribbean gorgonians by employing a common predatory Caribbean reef fish, Thalassoma bifasciatum, in ship-board bioassays (Pawlik et al. 1987). Over $50 \%$ of the extracts of 37 gorgonian types, representing at least 19 species and 11 genera, were scored as highly unpalatable to T. bifasciatum in these assays. Our results prompted more in-depth studies of 2 species, Pseudopterogorgia rigida (Harvell et al. 1988, Harvell \& Fenical 1989) and Erythropodium caribaeorum (Fenical \& Pawlik 1991). For $P$. rigida, the feeding deterrent properties of the extract were traced to 2 terpenoid compounds, curcuquinone and curcuhydroquinone, while a mixture of 
curcumene hydrocarbons had no deterrent effect (Harvell et al. 1988). For E. caribaeorum, the deterrent properties were traced to 2 chlorinated diterpenes, erythrolides B and D; again, a mixture of sesquiterpene hydrocarbons present in the animal tissues had no effect (Fenical \& Pawlik 1991).

In the present study, we turned our attention to Pterogorgia anceps, another gorgonian that scored as highly unpalatable in our initial assay (Pawlik et al. 1987). P. anceps is a shallow water gorgonian (depth range 7 to

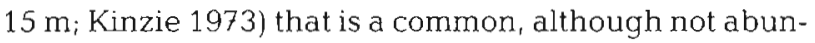
dant, member of the Caribbean reef fauna (see surveys from Jamaica: Kinzie 1973; Florida: Opresko 1973; Belize: Lasker \& Coffroth 1983; Puerto Rico: Yoshioka \& Yoshioka 1989). The predominant secondary metabolites of Pterogorgia anceps, bis-butenoides, are members of the distinctly different acetogenin class, a group of natural products derived directly from acetate precursors. In contrast, the deterrent metabolites of Erythropodium caribaeourm and Pseudopterogorgia rigida are terpenoids. Hydrocarbons are also present in high concentrations in the tissues of $P$. anceps. As before, we wished to determine the specific metabolites responsible for chemical defense.

\section{MATERIALS AND METHODS}

Gorgonian collection. Most of this study was completed during an expedition to the reefs surrounding the Bahama Island of San Salvador on board the research vessel 'Columbus Iselin' in July 1990. Approximately 20 colonies of Pterogorgia anceps were collected by SCUBA at ca $10 \mathrm{~m}$ depth from Cockburn Harbor. Colonies were air-dried for ca 2 to $4 \mathrm{~h}$ and all but 5 , chosen haphazardly, were frozen for later laboratory analyses. The distal branches of the 5 randomly chosen colonies were cut into small pieces for immediate extraction. Only the most proximal portions of most colonies of $P$. anceps have a thick endoskeleton, and these portions were discarded. An additional collection of $P$. anceps was obtained for comparative purposes from Belizian waters on board the 'Columbus Iselin' in June 1991

Extraction and isolation. The volume of the distal branch pieces of Pterogorgia anceps from the 5 freshly air-dried colonies was determined by moistening them with methanol (preventing absorption of solvent during the volumetric determination) and adding them to a known volume of a 2:1 mixture of dichloromethane $\left(\mathrm{CH}_{2} \mathrm{Cl}_{2}\right)$ and methanol in a graduated cylinder. The tips were then macerated in a blender and fully extracted with the same solvent mixture. The resulting extract was divided into 9 equal aliquots (each from $65 \mathrm{ml}$ of gorgonian tissue), dissolved in minimal amounts of diethyl ether and kept at $-20^{\circ} \mathrm{C}$ until used. One aliquot was used in field assays of the crude extract of $P$. anceps. One was saved for later laboratory analysis (unfortunately, it was lost; see 'Discussion'). The other 7 aliquots were combined and the secondary metabolites fractionated by vacuum flash chromatography on silica gel employing a 10 to $100 \%$ ethyl acetate in isooctane gradient. Isolation procedures were monitored by employing silica gel thin-layer chromatography (TLC) on Merck plastic-backed plates impregnated with fluorescent indicator and developed by heating after misting with a solution of $50 \%$ concentrated sulfuric acid in water. The least polar fractions yielded a mixture of hydrocarbons, which were combined into a single fraction designated ' $A$ '. The next more polar fraction yielded a mixture of typical sterols and fats. These were also combined into a single fraction designated ' $\mathrm{B}$ '. The next more polar fraction contained the strongly UV-active ancepscnolide compounds; it was designated ' $\mathrm{C}$ '. The most polar fraction, containing mainly pigments (mostly peridinins), was designated ' $D$ '. Portions of all 4 fractions were assayed in the ship-board laboratory and a portion of fraction ' $\mathrm{C}$ ' was further subjected to field assay (see below).

The remaining portion of fraction ' $\mathrm{C}$ ' (that which was not used in assays) was further separated by silica gel high-performance liquid chromatography (HPLC) on a preparative column with $70 \%$ ethyl acetate in isooctane as the eluant. This procedure yielded 5 pure compounds, designated 1 to 5 in order of increasing polarity. Ship-board bioassays were run on compounds 3 to 5 separately and together. Because they were minor components of fraction ' $\mathrm{C}$ ', compounds 1 and 2 were assayed together.

Structural assignments of secondary metabolites. The purifed compounds 1 to 5 from fraction ' $\mathrm{C}$ ' were analyzed by spectroscopic methods primarily involving mass spectrometry, UV and IR spectroscopy and NMR spectrometry. Comparison of the data obtained with those reported for previous compounds isolated from this and related gorgonians (Schmitz et al. 1966, 1969, Schmitz \& Lorance 1971) allowed confident structure assignments of all purified substances.

Quantitative analyses of Pterogorgia anceps secondary metabolites. The concentrations of ancepsenolide and related metabolites were quantified, at the Scripps Institution of Oceanography, for 5 samples from the Bahamas and 1 from Belize. Frozen samples were freeze-dried, dry weights were determined, and extracts were prepared as before. Quantification was performed by HPLC with the use of purified compounds 3 to 5 as standards. Standard curves were prepared with known concentrations of 3 to 5 and peak areas were calculated from known injection weights. 
Crude extracts were weighed and peak areas were compared to those of standards.

Field assays. The crude extract and fraction ' $\mathrm{C}$ ' isolated from the crude extract of Pterogorgia anceps were volumetrically reconstituted in a matrix of carrageenan at the same concentrations as they occurred in the gorgonian; strips of this matrix were then used in field experiments (see methods in Harvell et al. 1988 , Pawlik \& Fenical 1989, Fenical \& Pawlik 1991). The matrix was made by combining 3 to $4 \mathrm{~g}$ carrageenan (Gelcarin, FF961L; FMC Corp, Philadelphia, PA, USA) and ca $20 \mathrm{ml}$ of tuna fish puree (canned tuna in oil, pureed in a minimal volume of deionized water in a blender) with deionized water to a total volume of $65 \mathrm{ml}$. The mixture was heated to boiling in a microwave oven (about 1 min on 'cook'), then the extract in a minimal volume of solvent (treated matrix) or solvent alone (control matrix) was added. The mixture was stirred and heated again to boiling (extracts were previously judged to be stable to this treatment). The molten mixture was then poured into plastic molds crossed by lengths of cotton string that protruded from the ends of the molds. After the matrix cooled and gelled, $1.0 \times 0.5 \times 5.0 \mathrm{~cm}$ strips were sliced to size with a scalpel and removed from the mold. For each experiment, 20 treated strips and 20 control strips were prepared. To distinguish treated from control strips, the cotton string attached to each strips was marked with a small colored ink spot.

Field assay methods were based on those of Hay (1984) as modified by Pawlik \& Fenical (1989). One treatment and one control strip each were tied to a $50 \mathrm{~cm}$ length of 3-strand nylon rope at a distance of $\mathrm{ca}$ 4 and $12 \mathrm{~cm}$ from one end of the rope (the order was haphazard). Twenty ropes were deployed on the reef for each experiment, with the end of each rope opposite the food strips unwound and clamped onto a piece of coral or rock. All experiments were performed at 8 to $10 \mathrm{~m}$ water depth off San Salvador or Little San Salvador Islands, Bahamas. Identifications of fishes sampling food strips were made by consulting Randall (1983). Within $1 \mathrm{~h}$, the ropes were retrieved and the amount of each strip eaten was recorded as a percentage decrease in the strip length (to the nearest $5 \%$ ). The Wilcoxon paired-sample test (1-tailed; Zar 1984) was employed to analyze the results after excluding pairs for which both control and treatment slices had been either completely eaten, or not eaten at all.

On-board ship laboratory assays. Assays of fractions ' $A$ ' to ' $D$ ' and compounds 1 to 5 were performed on board the 'Columbus Iselin' by employing a common predatory reef fish, the bluehead wrasse Thalassoma bifasciatum. The advantages of using this species for aquarium bioassays have previously been detailed (Pawlik et al. 1987). Groups of 3 fish (1 blue- green, 2 yellow) were held in each of 13 divisions of volume ca $30 \mathrm{l}$ each in 4 large flow-through aquariums. Groups of fish were chosen at random during feeding assays and randomly offered either a treated or control food pellet, followed by the other choice. When the second pellet was treated, and was rejected, a third control pellet was offered to determine whether the fish had ceased feeding. Groups of fish that did not eat control pellets were considered satiated and were not used in the experiment. Pellets were considered rejected if not eaten after a minimum of 3 attempts by 1 or more fish to take them into their mouth cavity, or if the pellets were approached and ignored. The significance of differences in consumption of treated vs control pellets was evaluated with the Fisher exact test (Zar 1984).

Food pellets for laboratory assays were made by mixing a volume of $0.15 \mathrm{ml}$ of alginic acid (sodium salt) with tuna fish puree to a final volume of $2 \mathrm{ml}$, followed by addition of the volumetric equivalent of a fraction or compound in a carrier solvent (for treated pellets) or solvent alone (for control pellets). The mixture was vigorously stirred to remove lumps and then loaded into a $5 \mathrm{ml}$ syringe. The tip of the syringe was then dipped into a beaker filled with a $0.25 \mathrm{M}$ solution of $\mathrm{CaCl}_{2}$ and the contents of the syringe slowly expelled to form a long strand. After a few minutes, the strand was removed, rinsed in seawater, and chopped into ca $4 \mathrm{~mm}$ long pieces with a razor blade to form uniform pellets

\section{RESULTS}

Assay strips containing a crude dichloromethane/ methanol extract of Pterogorgia anceps at the same volumetric concentration as the extract occurs in the tissues of the gorgonian significantly deterred feeding of a natural assemblage of reef fishes $(p<0.0005$, Wilcoxon paired-sample test; Fig. 1). Food strips set out on the reef for this and the subsequent assay were primarily sampled by bluehead wrasse Thalassoma bifasciatum and yellowtail snapper Ocyurus chrysurus.

Flash chromatographic separation of the crude extract of Pterogorgia anceps yielded 4 fractions: the hydrocarbon fraction (' $\mathrm{A}$ '), the fraction containing sterols and fats ('B'), the UV-active ancepsenolidecontaining fraction (' $\mathrm{C}$ ') and the most polar, pigmented fraction (' $D$ '). Of these, only fraction ' $\mathrm{C}$ ' deterred feeding of Thalassoma bifasciatum in laboratory assays $(\mathrm{p}=0.000059$, Fisher exact test; Fig. 2). Fraction ' $\mathrm{C}$ ' also deterred feeding of a natural assemblage of reef fishes in field assays $(p<0.0005$, Wilcoxon pairedsample test; Fig. 3). 
CRUDE EXTRACT; $N=20(18), p<0.0005$

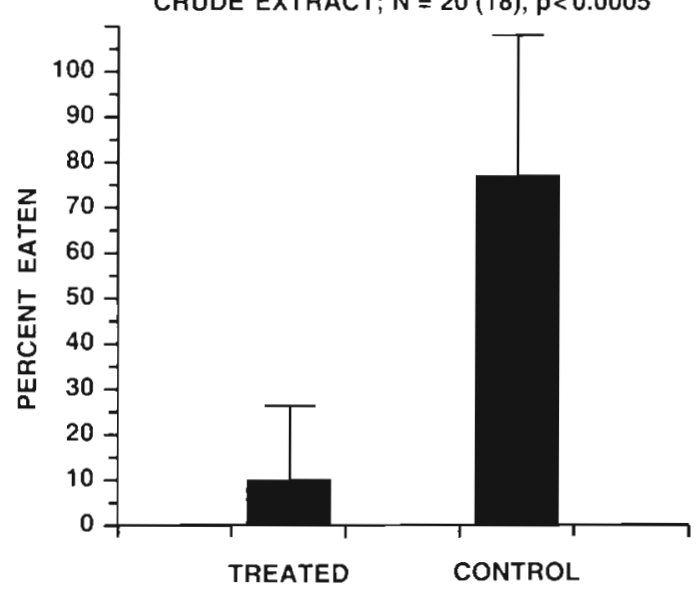

Fig. 1. Field assay. Consumption by reef fishes of paired control food strips and strips containing a crude extract of Pterogorgia anceps at the same concentration as found in the tissues of the gorgonian. $1 \mathrm{SD}$ above the mean is indicated. $N=$ no. of paired treatment and control strips retrieved of 20 deployed (no. of pairs used in statistical analysis). Probability calculated using the Wilcoxon paired-sample test

Fraction ' $\mathrm{C}$ ' was further separated into 5 pure compounds by HPLC. These were subjected to laboratory assays at concentrations volumetrically equivalent to those found in the tissues of Pterogorgia anceps. Compounds 1 and 2 were minor components of fraction ' $\mathrm{C}$ ', and were assayed together; they did not deter feeding of Thalassoma bifasciatum (Fig. 4). When compounds 3,4 , and 5 were assayed separately, only com-

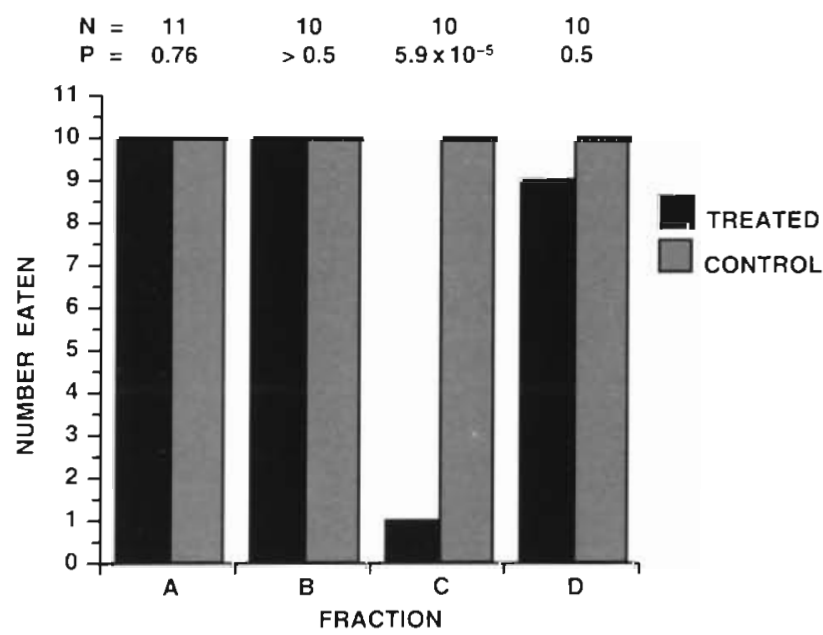

Fig. 2. Aquarium assay. Consumption by Thalassoma bifasciatum of control food pellets and pellets containing natural concentrations of $(A)$ the hydrocarbon fraction, $(B)$ the sterol fraction, (C) the ancepsenolide fraction, and (D) the pigmented fraction isolated from the crude extract of Pterogorgia anceps. Probabilities calculated using the Fisher exact test

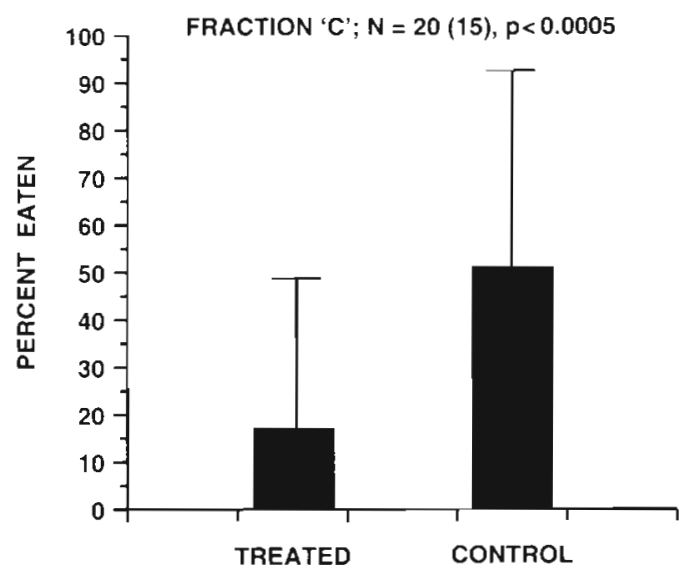

Fig. 3. Field assay. Consumption by reef fishes of paired control food strips and strips containing the natural concentration of the ancepsenolide fraction ( $C$ in Fig. 2). 1 SD above the mean is indicated. $\mathrm{N}=$ no. of paired treatment and control strips retrieved of 20 deployed (number of pairs used in statistical analysis). Probabilities calculated using the Wiicoxon paired-sample test

pound 5 deterred feeding of $T$. bifasciatum $(p=0.0005$, Fisher exact test; Fig. 4). Compounds 3 and 4 did not deter feeding when assayed separately, or in combination, unless compound 5 was also added to the mixture (Fig. 4).

Compounds 3,4 , and 5 were identified once samples were brought back to the Scripps Institution of Oceanography (Fig. 5). Compound 3, which made up $28.5 \%$ of fraction ' $\mathrm{C}$ ' was identified as ancepsenolide, a known compound previously identified from extracts of Pterogorgia anceps (Schmitz et al. 1966). Compound

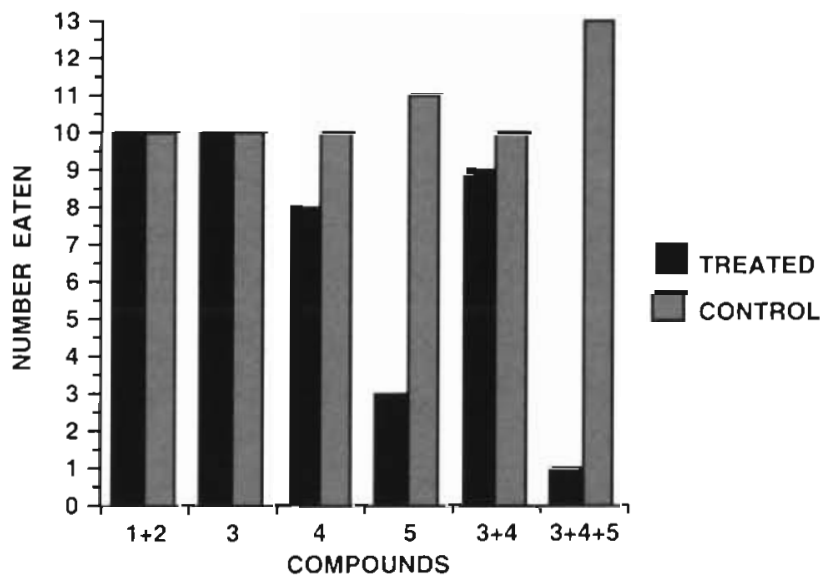

Fig. 4. Aquarium assay. Consumption by Thalassoma bifasciatum of control food pellets and pellets containing natural concentrations of subfractions 1 to 5 purified from fraction $\mathrm{C}$ of the crude extract of Pterogorgia anceps. Probabilities calculated using the Fisher exact test 

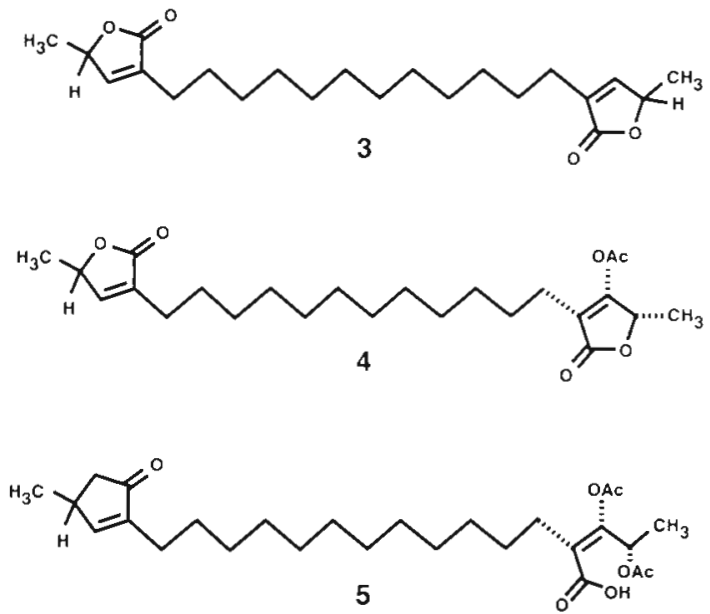

Fig. 5. Constituent compounds of subfractions 3 to 5 purified from fraction $\mathrm{C}$ from the crude extract of Pterogorgia anceps. Compound 3 is named ancepsenolide, compounds 4 and 5 are unnamed. Only compound 5 deterred predation in this study

4, which comprised $47.0 \%$ of fraction ' $\mathrm{C}$ ', was identified as an unnamed compound that had been produced as a synthetic product during a study of secondary metabolites from a closely related gorgonian, Pterogorgia guadalupensis (Schmitz et al. 1969). Compound 5 , the only deterrent compound in the mixture, made up $21.1 \%$ of fraction ' $\mathrm{C}$ ', and was identified as an unnamed compound that had been isolated as a natural product from Pterogorgia guadalupensis (Schmitz \& Lorance 1971).

The relative dry weights, expressed as percentages of the dry weight of the extracted gorgonian tissue, of the crude extract and compounds 3 to 5 for 5 individual colonies of Pterogorgia anceps from San Salvador Islands, Bahamas, and for 1 colony from Belize, were determined by extraction and quantitative HPLC (Table 1).

Table 1. Results of analyses of lipid-soluble extracts of 5 colonies of Pterogorgia anceps from San Salvador Island, Bahamas, collected 14 July 1990, and 1 sample from Belize, collected 11

June $1991^{\circ}$. Data are percentage of dry tissue weight

\begin{tabular}{|c|c|c|c|c|c|}
\hline \multirow[t]{2}{*}{ Sample } & & \multirow[t]{2}{*}{ Extract } & \multicolumn{3}{|c|}{ Compounds } \\
\hline & & & 3 & 4 & 5 \\
\hline SS-1 & & 3.27 & 0.17 & 0.35 & 0.08 \\
\hline SS-2 & & 3.39 & 0.24 & 0.46 & 0.11 \\
\hline SS-3 & & 3.08 & 0.15 & 0.27 & 0.23 \\
\hline SS-4 & & 5.15 & 0.24 & 0.25 & 0.47 \\
\hline \multirow[t]{3}{*}{ SS-5 } & & 6.48 & 0.14 & 0.28 & 0.72 \\
\hline & Mean & 4.27 & 0.19 & 0.32 & 0.32 \\
\hline & $\mathrm{SD}$ & 1.33 & 0.04 & 0.08 & 0.24 \\
\hline BEL-1 ${ }^{\bullet}$ & & 4.69 & 0.21 & 0.36 & 1.12 \\
\hline
\end{tabular}

\section{DISCUSSION}

Although the unusual secondary metabolites of gorgonians have long been assumed to play a role in chemical defense, this represents only the third study in which deterrent properties have been experimentally assigned to specific compounds. Previously, Harvell et al. (1988) determined that curcuhydroquinone and curcuquinone from Pseudopterogorgia rigida inhibited feeding of reef fishes in field assays, and Fenical \& Pawlik (1991) found a similar result for erythrolides B and D from Erythropodium caribaeorum. In addition, Wylie \& Paul (1989) demonstrated that a cembranoid diterpene from the Indo-Pacific alcyonacean Sinularia maxima inhibited the feeding of reef fishes when assayed at natural concentrations. As in the present study, each of these previous investigations assayed secondary metabolites that had no deterrent effects at natural concentrations; in particular, hydrocarbon compounds (curcumene and other terpenes from $P$. rigida: Harvell et al. 1988; a mixture of terpene hydrocarbons from Sinularia maxima: Wylie \& Paul 1989; erythrodiene and other terpenes from Erythropodium caribaeorum: Fenical \& Pawlik 1991; and a mixture of unknown hydrocarbons: this studyj. As discussed previously (Fenical \& Pawlik 1991), the ecological function of hydrocarbon compounds, which occur in high concentrations in the extracts of most gorgonians and alcyonaceans, remains to be determined.

Pterogorgia anceps had been ranked as a 'highly unpalatable' species in our preliminary survey of gorgonian chemical defenses (Pawlik et al. 1987). It. was chosen for further study because the secondary metabolites isolated from it were very different from the terpenoid compounds present in the 2 species previously chosen for in-depth experimentation (Pseudopterogorgia rigida and Erythropodium caribaeorum; Harvell et al. 1988, Fenical \& Pawlik 1991). The aliquot of crude extract of $P$. anceps that had been saved for laboratory analyses was lost in travel, so the dry weight concentrations of metabolites used in the field and laboratory bioassay experiments is not known. The extract, however, was taken from 5 colonies that had been randomly selected from a collection that included the 5 colonies that were chemically characterized separately (Table 1). Moreover, the HPLC-tracings from the ship-board purification of compounds 1 to 5 , taken from the extract that was assayed, were quantitatively similar to those of extracts of the 5 colonies that were characterized separately. The concentrations of metabolites that were assayed most probably fall close to the means observed for the 5 colonies that were fully analyzed (Table 1). The single colony from Belize exhibited the same chemistry as the colonies from the Bahamas, but had a 3.5-fold higher concentration of compound 5 in its 
tissues (relative to the mean concentrations of the Bahamas colonies). Inasmuch as this is the only compound that was found to deter feeding, this preliminary result suggests that there may be geographical variation in the abundance of compound 5, perhaps reflecting differences in the intensity of predation.

An interesting relationship exists between the structures of compounds 3,4 and 5 and their activities as feeding deterrents. Compound 3, or ancepsenolide, is a symmetrical bisbutenolide; half of this molecule is shared by compounds 4 and 5 with modifications only to the other half. The monoacetoxy derivative of this half (compound 4) was not a feeding deterrent, but additional oxidation to the diacetoxy derivative (compound 5) resulted in an effective feeding inhibitor. Compound 5 was also isolated as a natural product from Pterogorgia guadalupensis (Schmitz \& Lorance 1971), a species not examined in the present study. It seems likely that compound 5 functions in the same capacity for $P$. guadalupensis as for $P$. anceps. Surprisingly, the third species in the genus, $P$. citrina, was collected and extracted, and the extracts were analyzed by HPLC, but no ancepsenolide-related compounds were found.

Acknowledgements. Financial support for this research, and the use of the research vessel 'Columbus Iselin', was provided by grants from the National Science Foundation, Chemistry and Oceanography Divisions (CHE90-08621 to W.F.), and by an NSF Presidential Young Investigator Award (OCE9158065 to J.R.P.). We thank M. Boehler, M. Hay, J. Trischmann, and the captain and crew of the 'Columbus Iselin' for their assistance and cooperation in performing this research. We are grateful to the government of the Bahamas for permission to perform research in their territorial waters.

\section{LITERATURE CITED}

Faulkner, D. J. (1991). Marine natural products. Nat. Prod. Rep. 8: $97-135$

Fenical, W. (1982). Natural products chemistry in the marine environment. Science 215: 923-928

Fenical, W. Pawlik, J. R. (1991). Defensive properties of secondary metabolites from the Caribbean gorgonian coral Erythropodium caribaeorum. Mar. Ecol. Prog. Ser. 75: 1-8

Gerhart, D. J. (1984). Prostaglandin $A_{2}$ : an agent of chemical defense in the Caribbean gorgonian Plexaura homomalla. Mar. Ecol. Prog. Ser. 19: 181-187

Gerhart, D. J. (1986). Gregariousness in the gorgonian-eating gastropod Cyphoma gibbosum: tests of several possible causes. Mar. Ecol. Prog. Ser. 31: 255-263

Goldberg, W. M. (1973). The ecology of the coral-octocoral communities off the Southeast Florida coast: geomorphology, species composition, and zonation. Bull. mar. Sci. 23: $465-488$

Grigg, R. W. Polovina, J. J., Atkinson, M. J. (1984). Model of a coral reef ecosystem. III. Resource limitation, community regulation, fisheries yield and resource management. Coral Reefs 3: 23-27

Harvell, C. D., Fenical, W. (1989). Chemical and structural defenses of Caribbean gorgonians (Pseudopterogorgia spp.): intracolony localization of defense. Limnol. Oceanogr. 34: 382-389

Harvell, C. D., Fenical, W., Greene, C. H. (1988). Chemical and structural defenses of Caribbean gorgonians (Pseudopterogorgia spp.) I. Development of an in situ feeding assay. Mar. Ecol. Prog. Ser. 49:287-294

Harvell, C. D., Suchanek, T H. (1987). Partial predation on tropical gorgonians by Cyphoma gibbosum (Gastropoda). Mar. Ecol. Prog. Ser. 38: 37-44

Hay, M. E. (1984). Patterns of fish and urchin grazing on Caribbean coral reefs: are previous results typical? Ecology 65: 446-454

Huston, M. A. (1985). Patterns of species diversity on coral reefs. A. Rev. Ecol. Syst. 16: 149-177

Kinzie, R. A. (1973). The zonation of West Indian gorgonians. Bull. mar. Sci. 23: 93-155

Lasker, H. R. (1985). Prey preferences and browsing pressure of the butterflyfish Chaetodon capistratus on Caribbean gorgonians. Mar. Ecol. Prog. Ser. 21: 213-220

Lasker, H. R., Coffroth, M. A. (1983). Octocoral distributions at Carrie Bow Cay, Belize. Mar. Ecol. Prog. Ser. 13: 21-28

Lasker, H. R., Coffroth, M. A. (1988). Temporal and spatial variability among grazers: variability in the distribution of the gastropod Cyphoma gibbosum on octocorals. Mar. Ecol. Prog. Ser. 43: 285-295

McEnroe, F. J., Fenical, W. (1978). Structures and synthesis of some new antibacterial sesquiterpenoids from the gorgonian coral Pseudopterogorgia rigida. Tetrahedron 34: 1661-1664

Opresko, D. M. (1973). Abundance and distribution of shallow-water gorgonians in the area of Miami, Florida. Bull. mar. Sci. 23: 535-558

Pawlik, J. R., Burch, M. T., Fenical, W. (1987). Patterns of chemical defense among Caribbean gorgonian corals: a preliminary survey. J. exp mar. Biol. Ecol. 108: 55-66

Pawlik, J. R., Fenical, W. (1989). A re-evaluation of the ichthyodeterrent role of prostaglandins in the Caribbean gorgonian coral Plexaura homomalla. Mar. Ecol. Prog. Ser. 52: $95-98$

Randall, J. E. (1983). Caribbean reef fishes, 2nd edn., revised. TFH Publications, Neptune City, NJ

Schmitz, F. J., Krause, K. W., Ciereszko, L. S., Sifford, D. H., Weinheimer, A. J. (1966). Ancepsenolide: a novel bisbutenolide of marine origin. Tetrahedron Lett. 1: 97-104

Schmitz, F. J., Lorance, E. D. (1971). Chemistry of coelenterates. XXI. Lactones from the gorgonian Pterogorgia guadalupensis. J. org. Chem. 36: 719-721

Schmitz, F. J., Lorance, E. D., Ciereszko, L. S. (1969). Chemistry of coelenterates. XII. Hydroxyancepsenolide, a dilactone from the octocoral Pterogorgia anceps. J. org. Chem. 34: 1989-1990

Vreeland, H. V., Lasker, H. R. (1989) Selective feeding of the polychaete Hermodice carunculata Pallas on Caribbean gorgonians. J exp. mar. Biol. Ecol. 129: 265-277

Weinheimer, A. J., Matson, J. A. (1975). Crassin acetate, the principal antineoplastic agent in four gorgonians of the Pseudoplexaura genus. Lloydia 38: 378-382

Wylie, C. R., Paul, V. J. (1989). Chemical defenses in three species of Sinularia (Coelenterata, Alcyonacea): effects against generalist predators and the butterflyfish Chaetodon unimaculatus Bloch. J. exp. mar. Biol. Ecol. 129: 141-160

Yoshioka, P. M., Yoshıoka, B. B. (1989). A multispecies, multiscale analysis of spatial pattern and its application to a shallow-water gorgonian community. Mar. Ecol. Prog. Ser. 54: $257-264$

Zar, J. H. (1984]. Biostatistical analysis, 2nd edn. PrenticeHall, Englewood Cliffs

Manuscnpt first received: June 5, 1992

Revised version accepted: August 17, 1992 